\title{
OBJETIVOS COMO RAZÃO DE SER DA EMPRESA
}

* Raimar Richers

A determinação formal de objetivos estratégicos é, sem dúvida, uma das condições primordiais ao sucesso da empresa.

The statement of strategic goals is undoubtly one of basic conditions of a business success.

PALAVRAS-CHAVE:

Objetivos estratégicos, linha de conduta, alvos operacionais, missão.

KEY WORDS:

Strategic goals, line of conduct, operational targets, mission.

* Professor Fundador do De. partamento de Mercadologia da EAESP/FGV.

Revisitada por Luiz Tadeu A. Lopes, Mestre e Doutorando pela EAESP/FGV.

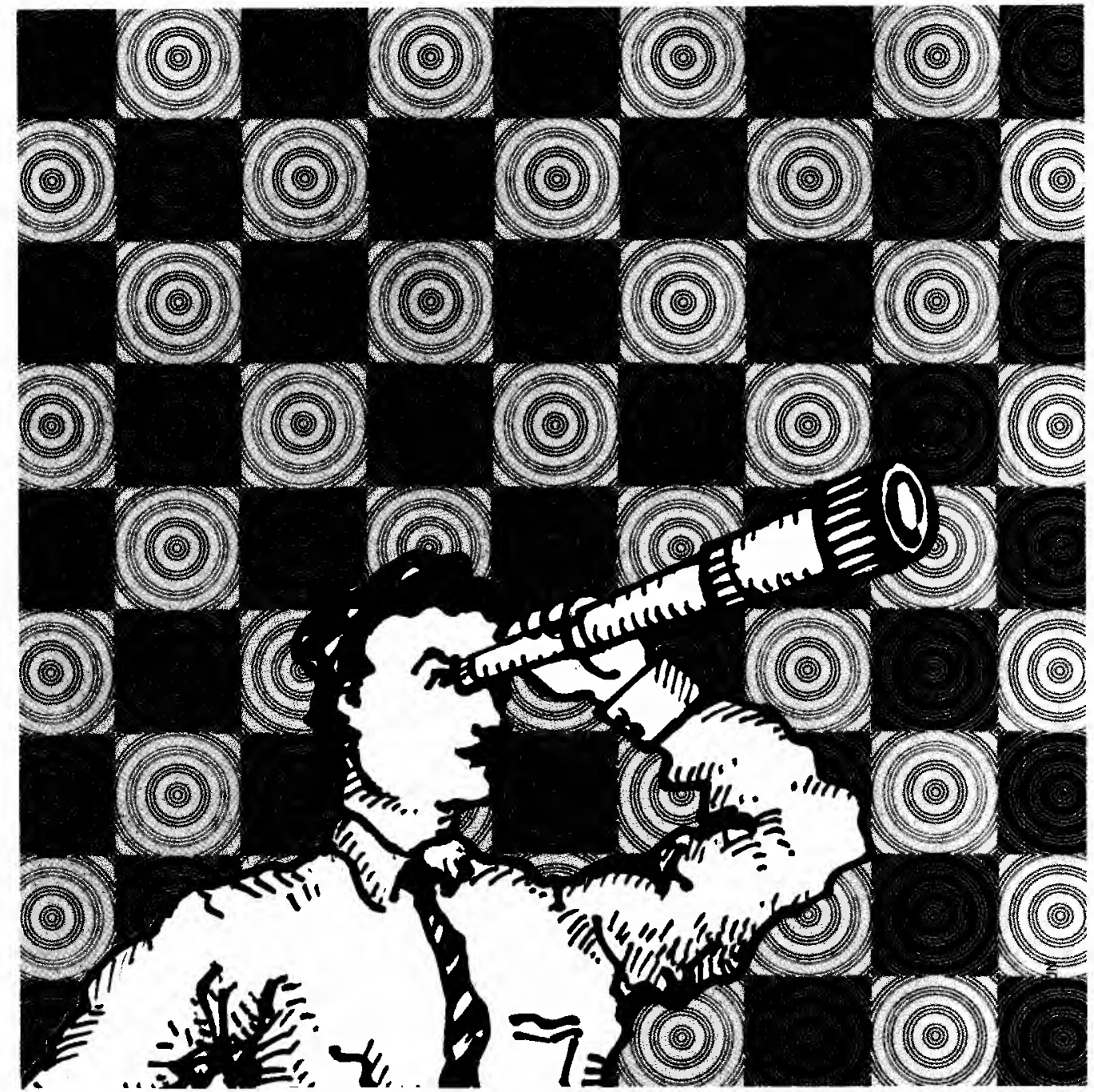

São Paulo, 34(1):50-62 


\section{INTRODUÇÃO}

Não há empresa sem objetivos. As organizações administrativas, segundo Herbert Simon", constituem-se de "sistemas de comportamentos cooperativos, onde se espera que os seus membros orientem seu comportamento de acordo com certos fins que são considerados como objetivos da organização". $\mathrm{Na}$ realidade, o que ocorre é que muitas empresas deixam de externar formalmente seus objetivos, embora isto não signifique que não os tenha. Portanto, uma coisa é ter objetivos, como condição de sobrevivência, uma outra é expressá-los.

A manifestação dos objetivos dependerá da determinação de uma série de fatores, dos quais são considerados como mais importantes:

- o tamanho da empresa. Pequenas empresas têm o planejamento estratégico restrito, devido à falta de recursos e de pessoal especializado. Além disso, e sobretudo, a estruturação formal da ação administrativa diminui a flexibilidade, imprescindível à sua própria existência. Na grande empresa, a ordem imposta pelo planejamento estratégico é essencial para evitar desperdícios e conflitos entre executivos. Portanto, à medida que a empresa for crescendo, seu funcionamento dependerá da definição destes objetivos;

- o tipo de empresa. Empresas com poder de decisão centralizado - geralmente familiares - necessitam menos de objetivos explícitos. Nas decisões voltadas a longo prazo, na dúvida, torna-se preferível não definir objetivos ou, como uma maneira de atenuála, concentrar as decisões de longo alcance nas mãos de uma minoria;

- a "maturidade" da empresa. Entendida como o grau de experiência que a alta gerência possui com o planejamento de longo prazo. Tal experiência é atrelada à cultura organizacional dentro da qual os objetivos são empregados como um ferramental.

Linda Smircich ${ }^{2}$ esclarece tal relação através da definição da cultura organizacional como "a cola normativa ou social que engloba a organização. Ela expressa os valores ou ideais sociais e as crenças que os mem- bros venham a dividir". Assim, conclui-se que o clima da empresa deve ser favorável e seus executivos propensos e preparados à discussão de problemas estratégicos para que se possa esperar que surjam definições significativas quanto aos objetivos de longo alcance.

Há outras variáveis que podem contribuir à decisão sobre se os objetivos devem ou não ser formalmente externados numa empresa. Seymour Tilles ${ }^{3}$ refere-se à mais forte delas ao colocar que explicitá-los seria uma maneira de avaliá-los ou aperfeiçoá-los. Neste texto, da mesma forma que em nosso artigo original, partimos da tese que pode ser assim resumida: para muitas empresas, não compensa a definição formal dos seus objetivos estratégicos. Todavia, à medida que cresce, descentraliza as suas responsabilidades e cria um ambiente interno voltado à praxe do planejamento por unidades operacionais, a determinação de objetivos formais torna-se uma das condições primordiais para assegurar o seu sucesso.

King e Cleland ${ }^{4}$ recomendam às organizações que desenvolvam uma declaração escrita de missão, devido aos benefícios que proporcionam:

- asseguram unanimidade de propósito dentro da organização;

- proporcionam uma base para a alocação de recursos organizacionais;

- estabelecem um tom geral ou clima organizacional;

- servem como ponto focal para os indivíduos identificarem-se com os propósitos da organização e para deter aqueles que a estes não se coadunam;

- especificam propósitos organizacionais e traduzem-nos em objetivos, de tal forma que custos, tempo e performance possam ser controlados;

- facilitam a tradução dos objetivos na estrutura organizacional.

O artigo propõe-se a expor um sistema conceitual e operacional de objetivos estratégicos que se aplica a qualquer empresa.

\section{O CONCEITO DE OBJETIVO ESTRATÉGICO}

Um objetivo organizacional é, segundo a definição de Amitai Etzionis, uma si-
1. SIMON, Herbert A. Administrative behavior. New York: Macmillan Company, 1947. Tradução para 0 português: Comportamento administrativo: estudo dos processos decisórios nas organizações administrativas. Rio de Janeiro: Editora da Fundação Getúlio Vargas, 1979.

2. SMIRCICH, Linda. Concepts of culture and organizational analysis. Administrative Science Quarterly, p. 339-58, September 1983.

3. TILLES, Seymour. How to evaluate corporate strategy. Harvard Business Review, v. 41, n. 4 , p. 111-21, July/August 1963.

4. KING. W. R., CLELAND, D. I. Strategic planning and policy. New York: Van Nostrand Reinhold, 1979. p. 124.

5. ETZIONI, Amitai. Modern organizations. Englewood Cliffs: Prentice-Hall, 1964. 
6. DRUÇKER, Peter. Managing for results. New Yark: Harper \& Row, 1964, p. 111

7. MOLZ, Rick. How leaders use goals. Long Range Planning. Oxford, v. 20, n. 5, p. 91-101, 1987.

\begin{tabular}{|c|c|c|}
\hline & Demonstrativo 1 & \\
\hline Aspectos... & $\begin{array}{l}\text { objetlyos estratégicos devem abranger... } \\
\text {...que respondern... }\end{array}$ & $\begin{array}{l}\text {...ans seguintes } \\
\text { itens da detiniçăa: }\end{array}$ \\
\hline $\begin{array}{l}\text { - direcionals } \\
\text { - tẹponorais } \\
\text { - titilitários } \\
\text { - polílico-administrativos } \\
\text { - decisórios } \\
\text { - motivacionais } \\
\text { - operacionais }\end{array}$ & $\begin{array}{l}\text { - onde se deve chegar ao adotar o objetivo; } \\
\text { - quando se deve chegar lá; } \\
\text { - quem deve se beneficiar ao se atingir o objetivo; } \\
\text { - como se chega ao consenso quanto ao abjetivo; } \\
\text { - quem deve procutar o consenso; } \\
\text { - quais sajo as origens psíquicas da escollha; } \\
\text { - o. que ceve ser telto para atingir o objetivo. }\end{array}$ & $\begin{array}{l}\text { posiçōes } \\
\text { projeladas } \\
\text { para a empresa } \\
\text { comzo um todo } \\
\text { aceitas pelos seus } \\
\text { dirigentes como } \\
\text { desejávels e exequivels }\end{array}$ \\
\hline
\end{tabular}

tuação desejada que a empresa tenta atingir. Os objetivos, no presente contexto, são os desígnios premeditados que valem para a empresa como um todo, que se referem a posições desejadas a serem conquistadas ao longo dos anos e que procuram antecipar-se a mudanças do meio ambiente e da adaptação da empresa a estas. São os objetivos de longo alcance e, sobretudo, os objetivos estratégicos (que prevêem alterações na relação empre$\mathrm{sa} /$ meio ambiente).

Peter Drucker6 identifica estas mudanças através do "amanhã", que sempre alcançará a empresa nos seus atuais esforços competitivos: "O propósito do trabalho de fazer o futuro não é decidir o que pode ser feito hoje para ter um amanhä". Se a organização năo está preparada para o "amanhã", seu risco de não poder lidar com as ameaças aumentará dramaticamente, bem como sua incapacidade de explorar oportunidades.

Os objetivos de longo alcance são gerados a partir de anseios humanos, mais ou menos visionários, quanto a uma situação futura que os satisfaça. Entretanto, para atingi-los, é preciso que o ser humano disponha de meios cuja aplicação conduza aos alvos imaginados.

Apesar de pouco estudados nos meios acadêmicos, os grids de estilos e processos de gerenciamento de objetivos são abordados por $\mathrm{Molz}^{7}$, ao analisar a influência de estilos gerenciais pessoais na condução dos grandes objetivos organizacionais.

Pelo menos dois elementos estão presentes na concepção de um objetivo: o psicológico, que envolve valores, atitudes, motivações e anseios de indivíduos; e o conjunto de instrumentos, composto de recursos (técnicos, financeiros, huma- nos etc.) que deverão ser aplicados para atingir os objetivos e satisfazer os anseios. Este instrumental é representado na empresa pelos seus recursos. Ela é, portanto, um meio para satisfazer desejos humanos. Toda a sua força é derivada da maneira como seres humanos utilizam seus recursos à luz de determinados alvos de longo alcance, que são os objetivos estratégicos.

A partir desta dualidade anseio/empresa (ou gerador/instrumento), conceituamos objetivos, genericamente, como a razão de ser de uma empresa. Mais especificamente, definimos objetivos estratégicos como posições projetadas para a empresa como um todo, aceitas pelos seus dirigentes como desejáveis e exeqüíveis.

Esta definição é derivada dos pré-requisitos implícitos na escolha de um ou vários objetivos de um plano estratégico. No demonstrativo 1, listamos esses sete pré-requisitos e sua ligação para com os elementos da definição. Da análise deste quadro, podemos derivar as seguintes considerações:

- para atender aos sete requisitos, a escolha do objetivo passará por um processo de triagem entre opções que abarcam uma multiplicidade de ações estratégicas, antes que se opte por um ou outro objetivo;

- este processo requer sondagens formais e informais quanto, por exemplo, à viabilidade e/ou à desejabilidade da adoção de objetivos, o que provoca conflitos, por vezes entre os dirigentes, e que devem conduzi-los a consensos em torno dos objetivos e de suas implicações quanto aos deveres e às responsabilidades implícitas na sua adoção; 
- dificilmente, um só objetivo atende a todos os pré-requisitos do demonstrativo 1. Daí, convém conjugar objetivos que procuram atender determinados fins do conjunto. Por exemplo, os alvos voltados ao crescimento e à diversificação de linhhas de uma determinada empresa refletem talvez primordialmente os anseios motivacionais de seus dirigentes, enquanto o dimensionamento desses alvos (expressos em volumes, taxas de retorno etc.) atende antes os aspectos operacionais e temporais da definição;

- como exercício de confrontos, conflitos e conciliações, o processo de escolha dos objetivos estratégicos de uma empresa é bem mais do que o esforço de formalização de idéias dos seus dirigentes. Alguns estudiosos, como Herbert Simon ${ }^{8}$ e Chester Barnard ${ }^{9}$, estabelecem que a adoção dos objetivos organizacionais está relacionada com a conciliação de interesses de grupos dominantes, visando à cooperação. $O$ processo de escolha implica também a sensibilização e o pré-estudo de alternativas de ação (para avaliar o grau de realismo de suas suposições e projeções). Por este motivo, o processo de triagem de objetivos já deve conter, em seu bojo, a essência da estratégia.

Certamente, não é esta uma tarefa fácil, nem sempre bem-sucedida nas empresas, mas válida em termos de perspectivas de retorno, por criar as bases para uma ação conjunta de dirigentes, que gera uma linguagem comum - ou ao menos inteligivel para todos -, concentra esforços e combate o desperdício de recursos e tempo.

\section{A HIERARQUIA DOS OBJETIVOS}

Uma das condiçốes para que a empresa consiga levar o processo de escolha de objetivos consiste em classificá-los a partir de algumas normas empíricas. Não que o processo de triagem deva ser iniciado com a classificação. Ele antes deve ser gerado através de manifestações espontâneas do tipo brainstorming. Mas, à medida que se chegue a idéias centrais ao longo dos debates, convém que se estabeleçam prioridades dentro de algumas categorias ou classificações.
Para orientar e facilitar esse processo, em nosso artigo original desenvolvemos um sistema hierárquico que parte das origens psíquicas (ou motivacionais) dos objetivos e os afunila ou racionaliza até a determinação de metas quantificáveis. Estas etapas compreendem os seguintes níveis:

\section{Nível I: escolha dos objetivos de gratificação}

No presente contexto, entendemos por gratificação a satisfação pessoal que os principais dirigentes da empresa procuram derivar das suas funções empresariais. Os objetivos da gratificação podem abarcar uma ampla gama de atitudes, va-

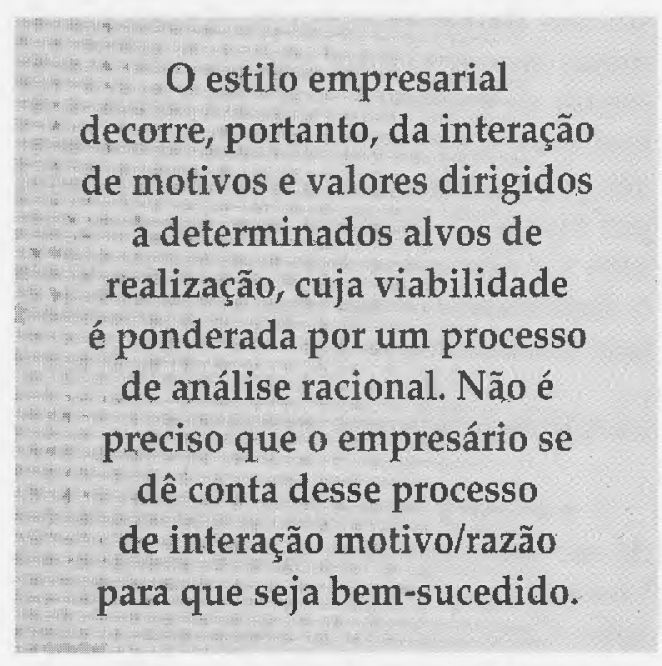

lores e motivações, todos eles voltados a atender um ou vários anseios do ego, através de ações que se utilizam da empresa como meio.

\section{Nível II: escolha do estilo empresarial}

O estilo empresarial consiste na tentativa de concretizar e consolidar os objetivos de longo alcance por meio de uma série de regras de comportamento, que constituem compromissos de longo alcance para os dirigentes e que procuram enfaixar a açăo administrativa dentro de certos preceitos, não necessariamente quantificáveis, mas nítidos quanto à escolha entre alternativas de caminhos.

Este nível envolve duas etapas de formulação: a primeira preocupa-se com a definição da missão da empresa; a segunda, procura qualificar as suas grandes linhas de conduta.
8. SIMON, Herbert A. Rationality of decision making in organizations. Nobel Foundation, 1979. Tradução para o português: Racionalidade do processo decisório em empresas. Rio de Janeiro: Ediçães Multiplic, 1980.

9. BARNARD, Chester I. The function of executive. Cambridge: Harvard University Press, 1938. Tradução para o português: As funções do executivo. São Paulo: Atlas, 1979. 


\section{Nível III: determinação dos alvos} operacionais

Identifica e qualifica as expectativas traçadas no passo anterior, ainda sem uma preocupação de precisá-las dentro de um determinado horizonte de tempo, mas já tendo em vista as melhores formas de sua operacionalização, seja em termos da disponibilidade de recursos, seja quanto à atribuição de tarefas de determinadas áreas funcionais da empresa.

\section{Nível IV: quantificação dos objetivos (escolha das metas)}

Metas são alvos específicos ou subjetivos delegáveis a unidades operacionais da empresa, a serem cumpridos em períodos e prazos predeterminados, expressos em dados numéricos. Exemplos de metas são: previsão por produto e segmento de mercado, cotas de venda a serem atingidas pelos vendedores em prazos preestabelecidos, retornos esperados por linhas de produtos etc. As metas devem ser derivadas dos alvos operacionais e constituem a base para os orçamentos (ver demonstrativo 2).

\section{OS COMPONENTES DA HIERARQUIA}

A estrutura hierárquica descrita pretende ser um meio para facilitar a tarefa de busca e classificação das prioridades de ação. Com esse intuito chega-se aos poucos a uma triagem de alvos específicos defensáveis pelos executivos, à luz de uma interpretação realística dos recursos da empresa e do ambiente que the envolve.

Para que o resultado desse processo possa ser ao mesmo tempo abrangente quanto à sondagem das opções estratégicas e realista em termos de viabilidades operacionais, uma multiplicidade de alternativas devem ser confrontadas entre si. No entanto, o melhor resultado desse esforço está na identificação de poucos objetivos e alvos operacionais integrados.

Para facilitar o processo de triagem convém traçar algumas considerações em torno de cada um dos quatro níveis da estrutura hierárquica.

\section{A gratificação como ponto de partida}

Por menos tangível que seja, a gratificação é a pedra angular de todo processo de escolha de objetivos, por representar o

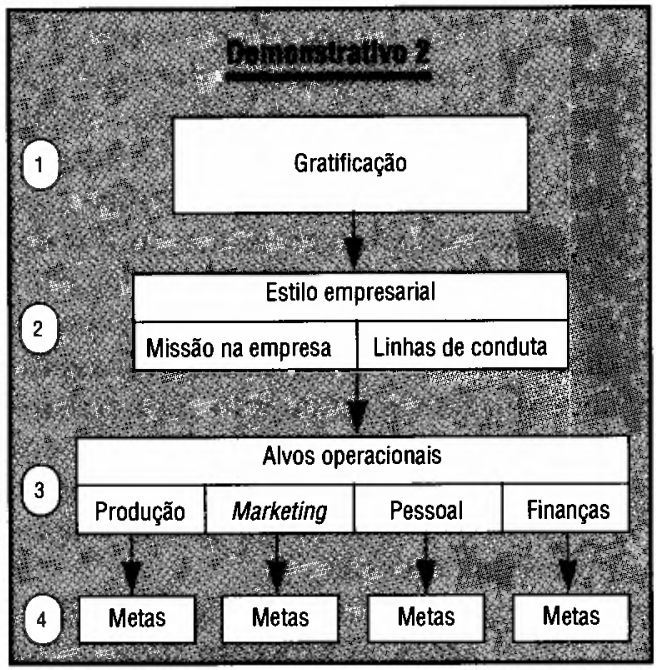

constante ponto de referência para os indivíduos empenhados em estabelecer objetivos e diretrizes. Neste sentido, ela pode constituir tanto obstáculo quanto estímulo a todos os passos posteriores. Ela gera obstáculos quando o dirigente sente conflitos entre os objetivos e a satisfação do seu ego. Em outras palavras, o dirigente jamais é inteiramente racional na sua escolha. O que ele procura é a consonância entre o seu "sonho" (ou estímulo motivacional) e algo tangível que a empresa pode supostamente lhe oferecer para realizar esse sonho.

As origens da gratificação podem ser quase que exclusivamente motivacionais ou derivar de um misto entre emoção e intenção racional. A gratificação sempre provém da personalidade do indivíduo $\mathrm{e}$, por este motivo, ela é, ao mesmo tempo, altamente intangível e resistente a influências que alterem os seus traços.

No entanto, não nos devemos iludir a respeito do elevado grau de influência que os valores pessoais exercem na formulação de diretrizes e objetivos em empresas onde as decisões são descentralizadas. Também nestas, eles são o combustível psicológico da geração de idéias. Lá, apenas, eles encontram um maior grau de resistência e contestação do que na empresa patriarcal, simplesmente porque o número de executivos que se acham no direito de influenciar os processos de decisão máxima é maior.

Dada a sua natureza subjetiva, a gratificação é um núcleo gerador de conflitos seja entre ideologias de grupos, seja para o indivíduo em si que se confronta com a si- 
tuação de ter que tomar decisões racionais à procura da consonância de seus valores.

$\mathrm{Na}$ prática da escolha de objetivos, a identificação dos motivos de gratificação é difícil ou até impossível, dada a sua natureza emotiva e personalista. As pessoas não se abrem perante terceiros, quanto aos seus anseios de longo alcance. No entanto, mesmo nos casos de motivações não externadas, justificam-se as lógicas dos objetivos. Isto é viável através da análise de manifestações e decisões tomadas por executivos de cúpula que refletem algo do seu ego e de suas motivações. Esta identificação torna-se tão mais fácil quanto mais um conjunto de decisões revela padrões de comportamento que permitem que se estime, por antecipação, as prováveis reações de indivíduos, o que pode contribuir à redução de conflitos internos e à economia de tempo e custos.

\section{A importância do estilo empresarial}

Do confronto entre elementos motivacionais e racionais resulta o que denominamos estilo empresarial ou a maneira como decisões de longo alcance são tomadas pelos dirigentes de empresas, a partir de sua personalidade e da interpretação de dados referentes ao meio ambiente. Esta interpretação resulta sempre de uma avaliação das oportunidades e ameaças que o empresário acredita precisar enfrentar para poder satisfazer os seus impulsos emocionais.

O estilo empresarial decorre, portanto, da interação de motivos e valores dirigidos a determinados alvos de realização, cuja viabilidade é ponderada por um processo de análise racional. Não é preciso que o empresário se dê conta desse processo de interação motivo/razão para que seja bem-sucedido. Nas decisões do dia-a-dia, talvez seja melhor que o processo seja antes intuitivo que ponderado. Entretanto, quando se trata de decisões de longo alcance e que envolvam o destino da organização como um todo, convém submeter este processo a uma análise bem minuciosa.

Quando da determinação de objetivos estratégicos, continuamos entendendo que esta análise deve abordar dois aspectos de ordem eminentemente qualitativa e filosófica. O primeiro é a definição da missão da empresa; o segundo visa a definir a linha de conduta que a empresa deve adotar na percepção de seus dirigentes.

\section{A caracterização da missão estratégica}

Peter Drucker ${ }^{10}$ coloca a dimensão exata à missão estratégica, quando observa: "Um negócio não é definido pelo seu nome, estatutos, artigos de incorporação. Ele é definido pela missão do negócio. Somente uma clara definição da missão e propósito da organização tornará claros e realistas os objetivos do negócio."

O pensamento corrente sobre a missão das empresas é baseado nas pesquisas e artigos de Peter Drucker, desenvolvidos em meados da década de 70, nos quais se coloca que responder à questão “Qual é nosso negócio?" corresponde a responder à pergunta "Qual é nossa missão?"

Ao volver a estas questões filosóficas, a cúpula administrativa não só define as áreas de ação prioritária nas quais devem ser aplicados os recursos à disposição, mas formula também uma espécie de credo, ou consenso de opinião, de que os esforços dirigidos a determinados alvos serão bem-sucedidos.

Anthony e Dearden'11 referem-se a tal aspecto quando colocam que o planejamento estratégico é o processo de decidir sobre os objetivos da organização, sobre as mudanças nestes objetivos, sobre os recursos usados para envolver estes objetivos e as políticas que governarão a aquisição, uso e disposição destes recursos.

Vejamos um exemplo da realidade empresarial que ilustra a complexidade e importância da missão como base para a formulação de objetivos. A declaração da missão na General Mills é simples: "Nossa missão é ser um líder entre as corporações. Nós nos empenharemos para conseguir a excelência em qualquer objetivo que nós nos comprometermos. Para cumprir esta missão, devemos ser sensíveis e premonitórios enquanto servimos nossos quatro componentes: consumidores, empregados, acionistas e a sociedade."

Pearce e David 12 descrevem que as declarações de missão das 500 maiores empresas classificadas pela Fortune freqüentemente incluem seis componentes: filosofia, autoconceito, imagem junto ao público, localização, tecnologia e sobrevivência.

Enquanto Cochran e David 13 que examinaram as declarações de missão de corporações e universidades, determinam oito componentes: fornecedor, pro-
10. DRUCKER, Peter. Management: tasks, responsabilities and practices. New York: Harper \& Row, 1973.

11. ANTHONY, R. N., DEARDEN, J. Management control systems. Irwin, 1976.

12. PEARCE II, J. A., DAVID, F. R. Corporate mission statements: the bottom line. Academy of Management Executive, p. 109-16, 1987.

13. COCHRAN, D., DAVID, F. R. The communication effectiveness of organizational mission statements. Journal of Applied Communication Research, 1987. 
14. WANT, J. H. Corporate mission. Management Review, p. 46-50, August 1986.

15. McGINNIS, V. J. The mission statement - a key step in strategic planning. Business Review, p. 39-43, November/December 1981. duto ou serviço, localização, tecnologia, sobrevivência, filosofia, autoconceito e imagem junto ao público.

Já Want ${ }^{14}$ considera como componentes primários da declaração de missão: propósito, identidade da organização, políticas da empresa, valores e princípio de ajuda ao negócio. O propósito é a justificativa para a existência da organização: as linhas primárias do negócio para a empresa, os produtos e serviços proporcionados e a maneira como são fornecidos. A identidade corporativa refere-se a como a empresa quer ser reconhecida no mercado por seus fornecedores, concorrentes, comunidades, empregados, para que se possa desenvolver um senso de identidade e compromisso com a empresa. As políticas da companhia compreendem a filosofia e o estilo de liderança da alta gerência, o perfil dos acionistas. Os valores dizem respeito à consideração para com os fornecedores, os competidores, os empregados e o público. Finalmente, os princípios de ajuda ao negócio incluem market share, lucratividade, produtividade e impacto sobre a competição.

McGinnis ${ }^{15}$ estabelece que a declaração de missão definirá o que a organização é, e o que aspira ser; limitará bastante alguns empreendimentos, assim como permitirá um crescimento criativo e distinguirá uma organização de outras. Ela também será utilizada como estrutura para avaliar tanto as atividades correntes quanto as futuras. Deverá ser suficientemente clara para que seja largamente entendida através de toda a organização.

Talvez a principal dificuldade ao se determinar a missão de uma empresa consiste em evitar o risco de uma abordagem ampla e comprometedora, sem cair no erro de uma definição.

A reavaliação da missão básica da empresa provoca uma reação em cadeia em toda a sua estrutura que pode levar a conseqüências profundas - tanto em termos positivos quanto negativos.

Dentro do contexto do planejamento estratégico, a missão exerce a dupla função de orientadora e delimitadora da ação empresarial. A escolha da missão não vai além dessa predeterminação. No entanto, ao delimitar o seu campo de atuação, a empresa costuma tomar a mais crítica das suas decisões estratégicas, as mais dificilmente reversíveis, por comprometerem conceitos e recursos para muitos e muitos anos.

\section{A escolha da linha de conduta}

Para poder cumprir a missão, a empresa dispõe de uma multiplicidade de caminhos e alternativas de ação. À opção consciente por uma destas alternativas, denominamos escolha da linha de conduta. Esta visa a orientar todas as diretrizes voltadas a médio e longo prazos que a empresa vier a adotar a partir do momento em que se decidiu por uma determinada missão empresarial.

Em termos abstratos, a variedade de linhas de conduta é ilimitada. Mesmo numa dada situação empresarial, as opções são múltiplas, embora limitadas por dois parâmetros: a relação oportunidades/ameaças que a empresa enfrenta no momento da escolha e os recursos de que ela dispõe para tirar proveito das oportunidades ambientais.

Ao avaliar esta relação entre os fatores endógenos e exógenos das principais opções de conduta, a empresa deve escolher entre uma (ou talvez uma combinação) das seguintes modalidades estratégicas:

1. a consolidação;

2. o crescimento;

3. a diversificação;

4. a ação social.

Conceituaremos, a seguir, cada uma dessas modalidades.

1. A consolidação das atividades se torna recomendável quando a empresa enfrenta ou espera encontrar dificuldades e prefere recuar ante às ameaças, podendo optar por dois tipos de objetivos gerais:

a. a sobrevivência como condição para atingir outros objetivos mais tangíveis (por exemplo, mais lucros, mais vendas etc.), não como objetivo exclusivo da empresa: sobreviver por sobreviver;

b. a estabilidade voltada à manutenção ou ao retorno a um estado de equilibrio ameaçado, por exemplo, pelo desajuste entre a capacidade instalada da empresa e seu poder de colocação de produtos no mercado. 
A adoção de uma estratégia de estabilidade envolve o abandono (por vezes passageiro) de uma posição antes conquistada, mas ameaçada. Por exemplo, a empresa gaúcha Conservas Oderich, viuse premida por um perigoso processo de descapitalização que ela mesma atribuiu a sua política de competir diretamente com grandes empresas (como a Swift, a Bordon e a Anglo) no mercado de alimentos. Para recuperar as suas forças, ela decidiu então restringir suas atividades a segmentos menos competitivos, através da reformulação da linha de produtos e política de distribuição.

Atitude semelhante foi adotada pela empresa suíça Prendar que conseguiu alcançar uma sólida posição nos mercados da Benelux no pós-guerra com sua linha de produtos de arame para uso caseiro. Todavia, quando resolveu ampliar os seus mercados para a França e Alemanha Ocidental, superestendeu a sua estrutura e estava prestes a perder os seus mercados originais. Ao verificá-lo, abandonou o plano de expansão e reduziu a sua linha de 1.400 a 400 artigos, concentrandose nos de maior contribuição marginal. A partir destas decisōes, recuperou a sua posição dominante nos seus mercados tradicionais.

2. A linha de conduta mais procurada pelas empresas é o crescimento ou a atenção voltada a multiplicar valores (como instalaçōes, linhas, produtos, número de empregados etc.) que já fazem parte do acervo experimental da empresa.

Há cinco modalidades de objetivos voltadas ao crescimento:

- a especialização;

- a inovação;

- a integração horizontal;

- a integração vertical;

- e a internacionalização.

Podemos falar em especialização quando os esforços de expansão da empresa são concentrados numa só ou em. poucas atividades de relação produto/mercado, freqüentemente com o intuito de conquistar ou manter a liderança de mercado nestas especialidades.
A especialização pode ser entendida como uma diferenciação cujo principal objetivo é a conquista da vantagem competitiva.

Alguns estudiosos se preocupam com o aspecto conceitual desta questão (ver Dickson e Ginter ${ }^{16}$. Atentaremos ao aspecto da especialização através do esquema estabelecido por Michael Porter, ${ }^{17}$ baseado na utilização da cadeia de valor agregado.

Porter visualiza uma distinção entre atividades primárias e as de suporte co-

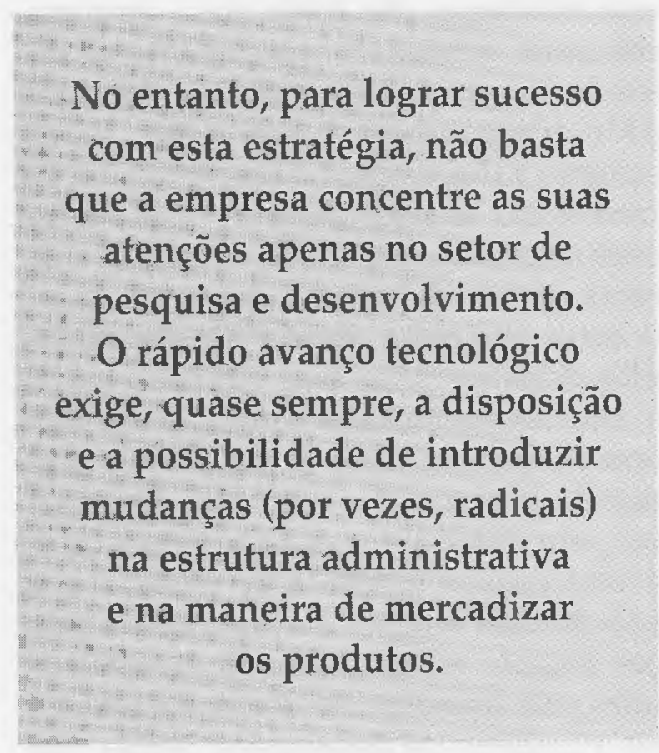

mo uma forma sistemática de ver a empresa. Sua cadeia de valor examina os custos em todas as áreas da empresa. Tal esquema deve permitir a quantificação em termos de valor definido como renda total e margem - e a comparação de seus custos com os de seus concorrentes.

Uma das fontes de vantagem competitiva é, segundo ainda o autor, a diferenciação. A especializaçẫo pode intensificar a diferenciação de duas maneiras básicas: através de uma singularização na execução de suas atividades de valor existentes ou de uma reconfiguração de sua cadeia de valores, intensificando sua singularidade. Como exemplo, apontamos a CocaCola, que utiliza uma segmentação baseada na estratégia de diferenciação por produto: Classic Coke, New Coke, Cherry Coke, Diet Coke, No Caffeine Coke - produtos estabelecidos dentro de um contexto por especialização e nicho de mercado.
16. DICKSON, Peter R., GINTER, James L. Market segmentation, product differentiation, and marketing strategy. Journal of Marketing, v. 51, p. 1-10, April 1987

17. PORTER, Michael. Vantagem competitiva, criando e sustentando um desempenho superior. Rio de Janeiro: Editora Campus, 1989. 
18. HAX, Arnoldo C., MAJLUF, Nicolás S. Strategic management - an integrative perspective. Englewood Cliffs: PrenticeHall, 1984.

19. KOTLER, Philip. Marketing. Edição compacta. São Paulo: Editora Atlas, 1980. p. 83

20. YOSHINO, M. Y. International business: what is the best strategy? The Business Quarterly, p. 64-5, Fall 1966.

21. AAKER, David A. Developing business strategies. John Wiley \& Sons, 2nd, 1988.
Por inovação, entendemos a dedicação a freqüentes lançamentos de produtos, visando a antecipar-se aos concorrentes. Hax e Majluf ${ }^{18}$ consideram as várias opções de uma inovação adequada, colocando que em mercados existentes podem-se encontrar novas aplicações para atuais usuários. O desenvolvimento de produto para o mercado atual pode ser uma fonte de inovação através da agregação de atributos, expansão de linha, novas gerações.

No entanto, para lograr sucesso com esta estratégia, não basta que a empresa concentre as suas atenções apenas no setor de pesquisa e desenvolvimento. $O$ rápido avanço tecnolóógico exige, qurase sempre, a disposição e a possibilidade de introduzir mudanças (por vezes, radicais) na estrutura administrativa e na maneira de mercadizar os produtos. A indústria relojoeira oferece alguns exemplos clássicos nesta área. No pós?guerra, a empresa americana Timex revolucionou o ramo ao explorar um grande segmento de mercado, totalmente descuidado pelo então líder (a indústria suíça). Tratava-se do mercado de pessoas que procuravam relógios estilosos mas a preços baixos. A Timex lançou diversas linhas para atender esta demanda, mas teve o cuidado de desenvolver novas vias de distribuição (como drogarias e lojas de varejo) para poder atingir o mercado de massa.

A quarta opção de crescimento é conceituada como crescimento integrado. Esta estratégia, segundo Philip Kotler, 19 faz sentido quando se verificam as seguintes condições: $a$ indústria básica apresenta um crescimento sólido; e a empresa aumentará a sua lucratividade, eficiência ou controle. Com base nestas colocações, identificam-se três tipos de crescimento integrado: para trás - através da posse ou controle dos sistemas de abastecimento; para a frente - por intermédio da posse ou controle dos sistemas de distribuição; e horizontal - através da posse ou controle dos concorrentes.

A quinta modalidade de crescimento é a internacionalização, uma das mais significantes tendências de negócio nas nações economicamente avançadas.

Yoshino ${ }^{20}$ estabelece, já em 1966, que mudanças básicas ocorreriam em relação às características dos negócios internacionais, que eram, até então, tradicionalmente operações do tipo exportação-importação. Um número crescente de empresas passaria a estabelecer plantas locais através de licenciamento ou investimentos.

Já David A. Aaker ${ }^{21}$ direciona a extensão do termo internacionalização para um conceito mais abrangente, a estratégia global. Esta pode ser contrastada com a estratégia multinacional, a qual é desenvolvida separadamente para diferentes países e implementada autonomamente. A estratégia global, ao contrário, é concebida e implementada em um âmbito mundial, pois as economias de escala não devem depender somente do market share local e sim estender-se a nível mundial. Além disso, alguns dos componentes de custo e produtividade devem ser localizados ao redor do mundo em busca das vantagens de custo.

É importante notar que concorrentes, mercados e tendências de outros países levam à identificação de importantes oportunidades, ameaças e questões estratégicas. Uma análise global externa é, no entanto, mais difícil por causa de diferentes culturas, riscos políticos e sistema econômico envolvido.

3. A diversificação é outra modalidade estratégica de que a empresa dispõe para ampliar as suas atividades. Segundo Kotler, o crescimento diversificado é adequado quando: o sistema central de marketing não demonstrar oportunidade adicional de crescimento ou lucro; e as oportunidades fora do sistema central de marketing forem superiores. No entanto, a empresa tenta identificar os campos que utilizam as suas características diferenciais e auxiliam a superar um problema.

Podemos considerar três tipos de diversificação: 1 . a concêntrica - na qual se adicionam novos produtos que tenham sinergia tecnológica e/ou de marketing com a linha de produtos existente, atraindo novas classes de consumidores; 2 . a horizontal - na qual novos produtos, que possam atrair consumidores atuais, são acrescentados, apesar de não estarem relacionados tecnologicamente à linha de produtos; 3 . a conglomerada - nesta adi- 
cionam-se novos produtos para novas classes de consumidores ou porque eliminam-se deficiências ou para aproveitar uma grande oportunidade ambiental.

É necessário examinar, ao considerar o crescimento, as motivações que levariam à diversificação. Bright ${ }^{22}$ lista algumas:

a. um desejo por maior crescimento do que as linhas de produtos atuais - a gerência, portanto, terá de avaliar cuidadosamente a proposta de novos produtos e clientes;

b. um anseio de usar lucrativamente uma nova tecnologia desenvolvida na empresa.

Para Thain, ${ }^{23}$ os riscos da diversificação serão grandes, diante das seguintes condições: ausência de habilidade ao formular e implementar a estratégia; ausência de visão gerencial para observar oportunidades de expansão; resistência da gerência às mudanças; mentalidade conservadora.

4. A última modalidade de conduta a ser mencionada é a que denominamos ação social. Ela é bem menos difundida do que as outras três formas. Entendemos por ação social as atividades produtivas e/ou distribuição, exercidas por instituições públicas ou privadas, que se propõem a criar e/ou promover benefícios para determinados grupos sociais, regiões ou mesmo para um país inteiro, sejam elas remuneradas por estes serviços ou não.

Apesar das discussões existentes, o Estado moderno ainda apadrinha o conceito da ação social como uma das bases do planejamento estratégico. Isto vale não somente para as empresas (e os órgãos públicos em geral) que lhe são afetos, mas também como ponto de partida para a formulação de leis e decretos que atingem a população como um todo.

As áreas que mais seriam afetadas por este tipo de legislação e/ou ação estratégica voluntária seriam as seguintes: a. a criação de empregos; $b$. a formação do homem (sobretudo das classes humildes) para melhor se adequar às tarefas das empresas modernas; c. a proteção de sua saúde física e mental; $d$. a segurança econômica do aposentado.
A contribuição que o planejamento estratégico pode oferecer à ação social não consiste tanto em motivar ou acelerar o desenlace dos processos sociais em si, mas antes no esforço de prever e avaliar os reflexos destes processos sobre a empresa do amanhã, e de estabelecer prioridades quanto a objetivos, diretrizes e medidas operacionais que se antecipam a estes reflexos. Neste sentido, a ação social se torna duplamente importante como objeto de análise da empresa privada. Em primeiro lugar, porque a empresa pode ser beneficiada, ou mesmo prejudicada, pelos reflexos da ação social gerada pelo governo, o que afetará a sua ação estratégica. Em segundo, porque a ação social pode ser provocada pela própria empresa, como parte integrante dos seus objetivos de conduta frente às comunidades com que ela mantém contato.

Em suma, a inclusão, entre os objetivos estratégicos, de considerações voltadas ao meio social da empresa justificase tanto para a instituição pública quanto para a empresa privada, em face do elevado grau de dependência de suas decisões de longo alcance da estrutura sócio-cultural do seu ambiente. $\mathrm{O}$ que se recomenda, pois, é que este tipo de consideração seja parte integrante do planejamento estratégico (por mais intangível que seja) desde a formulação dos objetivos que deverão orientar a ação administrativa de médio e longo alcances.

\section{Definição dos alvos operacionais}

Enquanto a busca do estilo empresarial é um processo eminentemente criativo, sinuoso e que se movimenta em ambientes por vezes nebulosos e imprecisos, o próximo passo - ou a determinação dos alvos operacionais - deverá e normalmente pode ser conduzido com um grau bem mais elevado de segurança e precisão. Isto se dá por duas razões:

- em primeiro lugar, os alvos operacionais permitem a identificação bem específica dos objetivos, se bem que ainda não necessariamente quantificados. Por exemplo, se a empresa optou pelo crescimento como forma básica de operação nos próximos cinco anos, os alvos operacionais devem lhe indicar
22. BRIGHT, W. M. Alternative strategies for diversification. Research Management, July 1969 .

23. THAIN, D. H. Stages of corporate development. Business Quarterly, p. 32-45, Winter 1969. 
24. WEINBERG, Robert. Apresentado no seminário Desenvolvimento de estratégias mercadológicas para lucros no curto prazo e crescimento a longo prazo, patrocinado pela Advanced Management Research, Regency Hotel, New York, 29 de setembro de 1969. de que maneira ela pretende chegar a esse objetivo central;

- em segundo lugar, os alvos operacionais são atribuíveis ou delegáveis a determinadas áreas específicas. Por exemplo, a operacionalização do alvo "modernizar e aumentar a eficácia do equipamento produtivo" muito provavelmente será atribuída à diretoria de produção, enquanto a implantação do alvo "elaboração de planos de incentivos mais racionais e mais justos" caberá à área de recursos humanos.

A ligação entre a escolha da missão, a linha de conduta e os alvos operacionais pode ser feita por meio da simples expressão "através de ...". Em outras palavras, alvos operacionais devem conter indicações claras, se bem que ainda não numericamente especificadas, quanto aos tipos de diretrizes que as diversas áreas de operacionalização devem adotar para atingir os objetivos estratégicos gerais da empresa.

Dos incontáveis exemplos de alvos operacionais que poderiam ser citados, um deles é de longe o mais discutido, seja nas empresas, seja na literatura técnica. Trata-se do lucro como objetivo. As nossas considerações sobre este assunto podem ser breves.

O lucro não é um bom alvo operacional. Evidentemente, a grande maioria das empresas não sobrevive sem lucratividade a médio e longo prazos. Uma coisa, no entanto, é a condição da sobrevivência em si, uma outra são os meios para se alcançar esta condição. O planejamento estratégico deve ir além da constatação de variáveis condicionantes (como o lucro) da sobrevivência da empresa. Ele deve também indicar caminhos que orientem a ação dirigida ao futuro. O lucro é útil para avaliar os resultados operacionais de um período passado, mas como norma operacional numérica a priori conduz os executivos a pensarem e agirem a curto prazo.

De outro lado, o conceito de longo prazo da lucratividade é totalmente inútil para fins de planejamento, por ser romântico no sentido de inviável e incontrolável.

Nada impede, no entanto, que a empresa inclua entre os seus objetivos estra- tégicos alguma sugestão quanto à lucratividade como algo desejável. Ao fazê-lo, contudo, ela deve estar ciente do fato de que, quanto maior for a sua ênfase à lucratividade como objetivo, tanto mais ela tende a inibir a tomada de decisões voltadas ao médio e longo prazos, porque estes freqüentemente implicam o sacrifício do lucro a curto prazo.

$\mathrm{O}$ aspecto lucro e o seu conflito com outros alvos operacionais, ao se traçar estratégias básicas para empresas é destacado por Robert Weinberg. ${ }^{24}$ Por exemplo: lucros a curto prazo $x$ crescimento a longo prazo; margem de lucro $x$ posição competitiva; objetivos de lucro $x$ não lucrativos (responsabilidade social).

Então, como sair da dicotomia: a lucratividade é necessária para a sobrevivência, mas pouco recomendável como alvo operacional? $\mathrm{O}$ que sugerimos é que a empresa recorra a conceitos que reúnam as três condições seguintes: primeira, que se prestem para a formulação de diretrizes operacionais aplicáveis a curto, médio e longo prazos; segunda, que contribuam de forma direta ou indireta à lucratividade da empresa; e terceira, que sejam mensuráveis.

O planejamento financeiro desenvolveu vários critérios que atendem a esses três requisitos:

- o retorno sobre o investimento - ROI (return on investment) que é a relação entre o lucro operacional e o ativo total da empresa. O ROI reflete a capacidade da empresa de gerar um lucro sobre um determinado montante de investimentos e, portanto, se presta não só para avaliar resultados operacionais da empresa como um todo, como também para ponderar os retornos esperados sobre futuros investimentos. $\mathrm{O}$ tema ROI pode ser variado de múltiplas formas, sendo que talvez as mais adequadas para fins de planejamento sejam as fórmulas que incluem a capitalização total da empresa, ou seja, todos os compromissos reais e suplementares - ROE (return on equity);

- o fluxo de fundos, particularmente o fluxo de caixa descontado (FCD). O fluxo de fundos para um período futuro da empresa quantifica (preferencialmente em termos de valores presentes) 
as mudanças que a empresa espera realizar nas principais contas do seu movimento financeiro, em termos de origens, de um lado, e aplicações do outro;

- a margem de contribuição - MC. No mundo empresarial moderno, este conceito tem ganho cada vez mais terreno, graças à sua simplicidade e utilidade operacional, seja como instrumento de controle, seja como base para a formulação de objetivos e diretrizes. A MC é a diferença entre as receitas da unidade de controle (como uma linha, produtos ou filial de venda) e os seus custos variáveis para um determinado período. Ela é a constatação do que esta unidade contribuiu para a cobertura dos custos fixos e da realização de lucros. Expressa em cruzeiros reais, ela reflete diretamente o volume de dinheiro que cada unidade gerou para cobrir os custos fixos e para produzir lucros. Expressa em percentagem, ela permite o confronto fácil entre as diversas margens, por exemplo, de uma linha. A partir deste confronto de periodos passados, a empresa pode reavaliar e reestabelecer novas metas operacionais para o futuro, seja para cada unidade individualmente, seja para o conjunto dos elementos que formam uma linha de produtos ou região geográfica.

A área financeira costuma dar origem a uma boa parte dos alvos operacionais, sobretudo àqueles que conduzem às metas. Na área de produção, os alvos giram primordialmente em torno de dois aspectos. Um deles são os custos operacionais e a sua racionalizaçăo como objetivo; o outro é a qualidade como medida de eficácia e dinamização tecnológica da produção. Na área de recursos humanos, os alvos variam consideravelmente, dependendo do grau de ênfase que a cúpula administrativa da empresa presta a esta área.

Na área mercadológica, observa-se hoje uma tendência de se enfatizar menos o volume de vendas globais da empresa como alvo operacional desejável que volumes crescentes (ou mesmo decrescentes) por segmento de mercado. Cada vez mais importante está se tornando a parti- cipação da empresa no mercado (em relação a outras empresas do ramo) como medida de eficácia e de determinaçāo de alvos operacionais, particularmente desde que se acumulam indícios da existência de uma correlaçäo elevada entre participação e ROI. Ademais, na área de marketing, a criação ou o fortalecimento de uma imagem favorável da empresa e/ou de seus produtos merece destaque entre os alvos operacionais (apesar das dificul-

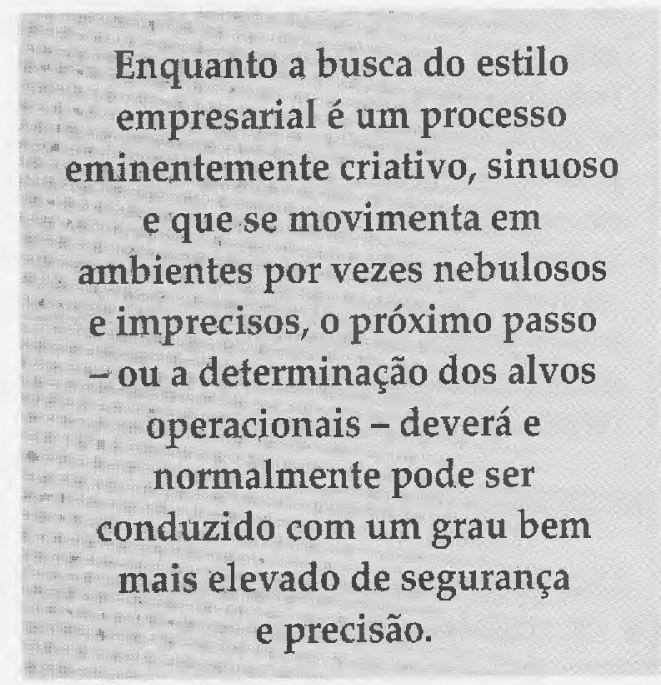

dades em se quantificar esta variável), por razöes diversas, tais como a influência da imagem de uma marca conhecida no lançamento de produtos novos ou a menor vulnerabilidade conjuntural das empresas que gozam de um alto prestígio no mercado.

\section{Determinação das metas}

Metas, como vimos, são subobjetivos, diretamente derivadas dos alvos operacionais, sempre expressas em números (cruzeiros reais e/ou unidades) e sempre referentes a determinados períodos.

Apesar de sua grande importância para assegurar uma transição racional entre as grandes linhas de conduta de um plano estratégico e sua operacionalização, serão poucas as nossas consideraçŏes em torno das metas, pois estas são antes uma função das táticas do dia-a-dia da empresa que do seu planejamento estratégico. No entanto, para serem eficazes, devem decorrer diretamente deste planejamento ao manterem o seguinte relacionamento para com os alvos operacionais: 
- elas devem ser derivadas diretamente daqueles alvos que são quantificáveis e jamais entrar em conflito com esses alvos;

- enquanto os alvos são estabelecidos para prazos médios, as metas se referem a períodos curtos (até um ano);

- enquanto os alvos apenas orientam a ação administrativa das áreas operacionais, as metas constituem a base para a delegação específica de tarefas nestas áreas (tais como o planejamento de produção de uma determinada linha para um determinado período pré-especificado);

- os alvos constituem o ponto de partida para a execução de dois instrumentos de execução do plano estratégico: o orçamento e a aplicação dos sistemas de controle. As metas dimensionam os objetivos dentro dos moldes e períodos orçamentários e servem como padrões de referência para o sistema de controle.

\section{CONSIDERAÇÕES FINAIS}

Objetivos são essenciais à sobrevivência da empresa. Eles asseguram um mínimo - por vezes um alto grau - de unidade de ação ao seu corpo administrativo. Ao discuti-los e reformulá-los, eles nos ajudam a melhor equacionar perguntas, tais como: Onde se situa a empresa hoje e para onde vamos encaminhá-la no futuro? O que podemos esperar como resultados ao agir desta ou daquela forma? O que deve representar a empresa, atualmente e dentro de um futuro previsível, para os seus proprietários, seus públicos-alvo e para a sociedade a que pertence?

Quão precisas poderão ser as respostas a estas perguntas depende de uma multiplicidade de fatores, como a estrutura funcional da empresa, seus padrões de liderança e delegação, seus dados e seu tamanho, do ramo em que ela opera e das informações disponíveis a seu respeito, de sua vivência no passado e do grau de sensibilidade de seus dirigentes ao interpretarem esta experiência, de sua maturidade como um órgão de intercomunicação humana e certamente também da predisposição de sua cúpula administrativa de dedicar recursos e tempo à busca sistemática de objetivos. De fato, o número de variáveis que afetam o jogo de perguntas/respostas sobre os objetivos da empresa é tão amplo que ele se torna, para muitos, fortuito e teórico. Não obstante, como em todas as questốes de ordem estratégica, os ganhos potenciais dos que participam deste jogo não consistem na garantia de encontrar soluções precisas para problemas intangíveis, mas na conquista do consenso em torno de alguns alvos imaginários, idealmente percebidos e aceitos pelo grupo empresarial e para o qual convergem recursos e esforços.

Esta conquista jamais se realiza de um só lance. Ela requer diálogos, por vezes a solução de conflitos, e a freqüente ponderação de alternativas. Ela se processa por etapas que obedecem a uma lógica própria, imperceptível talvez para quem participa desta evolução, mas que, costumeiramente, começa com os anseios subjetivos dos que se sentem responsáveis pelos destinos da empresa, e que, aos poucos, são decodificados e traduzidos em mensagens compreendidas e aplicáveis por executivos de linha e de staff.

Com o intuito de facilitar esta tarefa de triagem e afunilamento de idéias e diretrizes em torno dos objetivos estratégicos da empresa, o artigo reproduz o sistema descrito na versão original. Esse sistema estabelece quatro níveis de análise que partem da visăo genérica e subjetiva do objetivo como sonho, atravessam várias fases de confronto entre desejos e viabilidade para, finalmente, conduzir à formulaçăo de alvos e metas quantificáveis e delegáveis aos setores operacionais.

Desde a publicação original deste artigo temos proposto às empresas desejosas em reformular a sua política de objetivos a utilização deste modelo como esquema de trabalho que não necessariamente deve ser seguido à risca - etapa por etapa - mas que lhe sirva como "ma$p a^{\prime \prime}$ de orientação à busca de seu próprio caminho. $\square$

Artigo revisto por Mirtes Cristina A. Santos,

Mestranda na FEAVUSP.

O presente artigo é uma versão reduzida do artigo original publicado pelo professor Raimar fichers, na RAE - Revista de Administração de Empresas, sob o mesmo título, em julho/setembro de 1980 . A inclusäo de referências bibilográficas mais recentes se fazem presentes nesta atualização. 